\title{
BMJ Open Perceived health after percutaneous pulmonary valve implantation: in-depth interviews of patients and next-of-kin
}

\author{
Brith Andresen, ${ }^{1,2}$ Marit Helen Andersen, ${ }^{3}$ Harald Lindberg, ${ }^{2,4}$ Gaute Døhlen, ${ }^{5}$ \\ Erik Fosse ${ }^{1,4}$
}

To cite: Andresen B Andersen $\mathrm{MH}$, Lindberg $\mathrm{H}$, et al. Perceived health after percutaneous pulmonary valve implantation: in-depth interviews of patients and next-of-kin. BMJ Open 2014:4:e005102. doi:10.1136/bmjopen-2014005102

- Prepublication history for this paper is available online To view these files please visit the journal online (http://dx.doi.org/10.1136/ bmjopen-2014-005102).

Received 20 February 2014 Revised 10 June 2014 Accepted 7 July 2014

\section{CrossMark}

\footnotetext{
${ }^{1}$ The Intervention Centre, Oslo University Hospital, Oslo, Norway

${ }^{2}$ The Department of Cardiothoracic Surgery, Oslo University Hospital, Rikshospitalet, Oslo, Norway ${ }^{3}$ Division of Cancer Medicine, Surgery and Transplantation, Oslo University Hospital, Rikshospitalet, Oslo, Norway ${ }^{4}$ Faculty of Medicine, Institute for Clinical Medicine,

University of Oslo, Norway

${ }^{5}$ The Department of Pediatric Cardiology, Oslo University Hospital, Rikshospitalet, Oslo, Norway
}

Correspondence to Dr Brith Andresen; brandres@ous-hf.no

\section{ABSTRACT}

Objective: Percutaneous pulmonary valve implantation is an alternative to open heart surgery in selected patients with pulmonary outflow tract disorder. The technique may reduce the number of open-chest surgeries in these patients. This study was conducted to understand how the patients and their next-of-kin experienced this new treatment option.

Design: Qualitative explorative design with individual indepth interviews.

Setting: Oslo University Hospital, the only cardiac centre in Norway offering advanced surgical and interventional treatment to patient with congenital heart defects, serving the whole Norwegian population.

Participants: During a 2-year period a total of 10 patients, median age 17 (7-30) and 18 next-of-kin were consecutively selected for individual in-depth interviews 36 months after the pulmonary valve implantation. The verbatim transcripts were analysed using a phenomenological methodology.

Results: Patients emphasised the importance of regaining independence and taking control of daily life shortly after the new interventional treatment. Renewed hope towards treatment options was described as 'a light in the tunnel'. Next-of-kin emphasised the importance both for the patient and their family of resuming normal life quickly after the procedure. The physical burden was experienced as minor after the minimally invasive intervention, compared to their previous experience with surgical procedures.

Main outcome measure: The importance of maintaining normality in everyday life for a good family function.

Conclusions: The repeated surgeries during infancy and adolescence of patients with congenital heart disease represent a heavy burden both for the patient and their family. All families especially emphasised the importance of resuming normal life quickly after each procedure. The novel technique of pulmonary valve implantation is thus a favourable approach because of minor interference in daily life.

\section{INTRODUCTION}

Advances in surgical and interventional techniques and medical care create new life

\section{Strengths and limitations of this study}

- Data were collected through in-depth interviews and it thereby reflects actual experiences.

- The qualitative approach gave a deeper and unique understanding of the patients and their relatives' experiences in early rehabilitation phase after the percutaneous pulmonary intervention.

- The study was framed in the concepts of Western medicine and values. It is possible that the experiences would differ in a different cultural or geographical setting.

- There were few citations from the younger children and therefore a possible lack of information within this group. The broad age differences were challenging in gaining in-depth knowledge within each group.

- This is a short-term follow-up study, and there may be a bias towards positive results due to gratefulness of patients and relatives.

expectations in patients with congenital heart disease. To date, approximately $90 \%$ survive to adulthood and constitute a relatively new and growing patient population, ${ }^{1}$ increasing with an estimate of $5 \%$ per year. ${ }^{2}$ Approximately 8 of 1000 children are born with congenital heart disease, of these $10 \%$ have a pulmonary valve abnormality. ${ }^{3}$ These patients typically undergo palliative or corrective surgery early in life. ${ }^{4}$ Living longer, they are in need of an increasing number of surgical interventions when they outgrow the size of a replaced conduit or when the pulmonary valve becomes stenotic or insufficient. ${ }^{5}$ Recurrent changes in their health, ${ }^{6}$ initiate new treatment demands. A mean length of a hospital stay after a change of the pulmonary valve was 5.7 days with a mean stay of 2.8 in the intensive care unit. ${ }^{7}$ Patients treated with percutaneous pulmonary valve implantation went home 1 day after treatment. ${ }^{7}$ In a limited number of studies investigating experiences in patients with congenital heart disease using qualitative methods, normalisation is documented to be a 
central issue. ${ }^{6}{ }^{8-10}$ In a study of 11 patients treated for single ventricle physiology, the patients emphasised the limitations in their physical and social activities as a main problem. To compensate for the lack of physical performance they were adapting to alternative roles during physical activity and pursuing academic interests in order to obtain social recognition. ${ }^{9}$ This finding was confirmed in a Norwegian study of 11 children with congenital heart disease, ${ }^{8}$ referring to qualitative data. Authors concluded that children used different strategies to participate and to fulfil their first priority which is to be together with other children. ${ }^{8}$ Repeated major surgeries may add to this challenge. ${ }^{6}$ Percutaneous pulmonary valve implantation is a minimally invasive technique that rapidly has become an alternative option to surgery to restore pulmonary valve function. ${ }^{4}$ In order to evaluate and understand the importance of this minimally invasive technique, we conducted qualitative interviews of patients and their next-of-kin. The aim was to investigate whether this treatment technique influenced individual perceived health and reduced some of the burden in their daily lives in the early rehabilitation phase after treatment.

\section{METHODS}

Design

A qualitative, explorative design was chosen to generate a deeper understanding of the experienced outcome for each individual. Data was collected through in-depth interviews with the patients and their next-of-kin.

\section{The institution}

Norway has a national healthcare system with a health assurance offering the same treatment to each individual, independent of income. The study was conducted at Oslo University Hospital, the only cardiac centre in Norway offering advanced surgical and interventional treatment to patients with congenital heart defects, serving the whole Norwegian population.

\section{Participants}

During a 2-year period 10 patients: 3 girls of median age $17(10-30)$ and 7 boys of median age 18 (7-28) met the inclusion criteria and were treated with percutaneous pulmonary valve implantation. Patients were consecutively included in the study, and all informants spoke and understood Norwegian. The patients and their next-of-kin were included with informed consent. Inclusion was based on internationally accepted treatment criteria within this medical field, and a consensus set by the local team responsible for the patients. The selection criteria were also based on guidelines delineated by the producer of the device. The patients had previously in median undergone 3 (2-5) open heart surgeries.

\section{Interviews}

The study was based on in-depth, audio-taped interviews. To record experiences related to the intervention and the rehabilitation situation, all patients and their next-of-kin were interviewed between 3 and 6 months after the procedure. All interviews took place in a quiet room in the hospital, and lasted for approximately $1 \mathrm{~h}$. We think that the number of participants was adequate for the research method because the in-depth interviews provided us with a large amount of information sufficient to detect patterns. The interview guide contained the following themes: (1) life satisfaction in the early rehabilitation period; (2) experiences of physical, psychological and social limitations; (3) family and friend network and (4) life perspectives. A semistructured interview guide guaranteed that predetermined issues were covered during the interview. In the interview we used open-ended questions. We started the interview with: "How are you? How did you experience your rehabilitation after your last treatment? How was the influence in every day living? These are examples of questions. Modifying the interview according to the patient's age was done mainly by following up of their answers. The children and teenagers needed more following up questions compared to the grown-ups in general. The main concern then was to try to get the patient to elaborate the experience in order to get as rich information as possible.

Concerning the interview of the next-of-kin, the questions were open and questioned in a way that explored her/his experiences on how the rehabilitation situation influenced their child, and their family life in daily living.

At the end of the interview the participants were asked if they had anything to add. All informants were given the opportunity to discuss their interview situation and to add other or related experiences.

\section{Data analysis}

The interviews were first transcribed verbatim and then analysed and reported separately. The process of analysis was based on a phenomenological approach according to a previously described methodology. ${ }^{11}$ In brief, first, the whole interview was read to get a general impression. Second, the text was divided into units of meaning, in order to grasp the most probable interpretation. Third, the person's answer was read with the aim to be without prejudice and the theme that dominated a meaning unit was stated as simple as possible. Fourth, 'expressive units' related to the aim of the study were sought. These units were then condensed and coded. In the fifth step, the essential themes of the entire interview were tied together in a descriptive statement. The method thus involved condensation of the expressed meaning into a more essential formulation of the experience following the percutaneous pulmonary valve implantation. ${ }^{11}$

\section{Data quality}

To assure data quality, two researchers were present at each interview. One of the researchers led the interview and the other added supplementary questions when 
necessary. Data analysis was performed mainly by two researchers to obtain the patients and next-of-kin's opinions. All researches were participating to strengthen accurate reflection, highlight differences and reach final consensus.

\section{Ethical considerations}

All participants were provided with oral and written information about the aim and the design of the study. One of the patients was mentally retarded and did not want to speak with the researcher. In this case we chose to include data from next-of-kin. Another patient had Di-George syndrome with some degree of retardation. $\mathrm{He}$ was interviewed with a modified interview guide according to an evaluation of his ability to answer.

\section{RESULTS}

Demographic and medical data are presented in table 1. The informants' experiences are grouped in two parts: patients' experiences (figure 1) and experiences of next-of-kin (figure 2).

\section{Patients' experiences}

The main finding evolving throughout the interviews was the significance of regaining independence and taking control of daily life shortly after the new interventional treatment. Second, the ability to fulfil everyday roles and to be in physical control shortly after treatment was emphasised as important by all patients. Third, renewed hope towards treatment and treatment

\begin{tabular}{|c|c|}
\hline \multicolumn{2}{|l|}{ Gender } \\
\hline Men & 7 \\
\hline Women & 3 \\
\hline \multicolumn{2}{|l|}{ Original diagnoses } \\
\hline $\begin{array}{l}\text { Tetralogy of Fallot, all } \\
\text { variants }\end{array}$ & 6 \\
\hline $\begin{array}{l}\text { Truncus arteriosus } \\
\text { communis }\end{array}$ & 3 \\
\hline $\begin{array}{l}\text { Aorta stenosis, } \\
\text { Ross-operated } \dagger\end{array}$ & 1 \\
\hline \multicolumn{2}{|l|}{ Right ventricle outlet } \\
\hline Valve conduit & 6 \\
\hline Homograft & 3 \\
\hline Biological valve (Perimount) & $\begin{array}{l}1 \\
\text { Median (range of } \\
\text { variation) }\end{array}$ \\
\hline Age (years) & $17(7-30)$ \\
\hline Weight (kg) & $66(28-98)$ \\
\hline Height $(\mathrm{cm})$ & $172(132-177)$ \\
\hline \multicolumn{2}{|c|}{$\begin{array}{l}\text { *One patient with pulmonary atresia and ventricular septal defect } \\
\text { known as an extreme variant of tetralogy of Fallot. } \\
\text { †By Ross-surgery the native pulmonary valve is moved into an } \\
\text { aortic position; by this procedure an artificial outlet is implanted } \\
\text { from right ventricle. }\end{array}$} \\
\hline
\end{tabular}

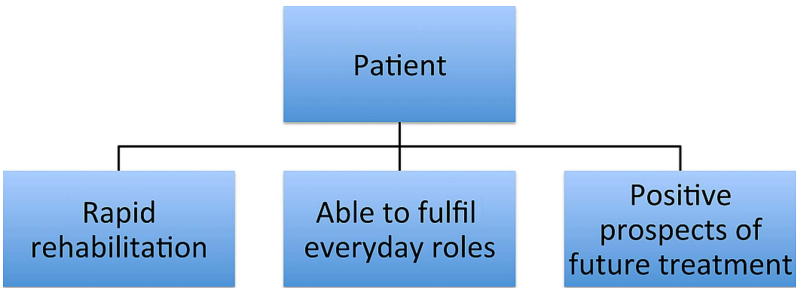

Figure 1 Experiences of patients. Main categories emerging from the interviews.

options contributed to positive feelings towards future life.

\section{Rapid rehabilitation}

The easier pathway during the two first days after treatment was highly regarded and addressed in different ways: "The rehabilitation period was different this time, I walked over to visit a friend the day after the percutaneous implantation and overall, my social life was hardly affected at all". The experience of no or minimal pain or discomfort in the early postoperative period was communicated and stated as an important issue by three patients: "Everything was normalized faster after this intervention. When they cut me open, it was like having all my ribs fractured. Now there was hardly pain at all". Another statement was: "I feel I tolerate less and less pain as time passes, so it is lovely to avoid surgery. I got my daily life back much faster this time".

\section{Being able to fulfil everyday roles}

The experience of regaining independence and taking control of life shortly after the intervention was praised. This meant resuming the ability to fulfil roles related to one's own expectations, for the children to 'hang out with friends' doing ordinary things. One of the girls expressed her view on her physical endurance and her thoughts about her role among peers: "No matter, I am always the one who is behind the others physically in class. But there is something I can do, I can help the others with schoolwork etc." Her main concern seemed to be her ability to join her peers and to be included socially by participating. One adult female patient described the psychological and emotional strain relief following this intervention experiencing the ability to attend socially and take care of her children shortly after

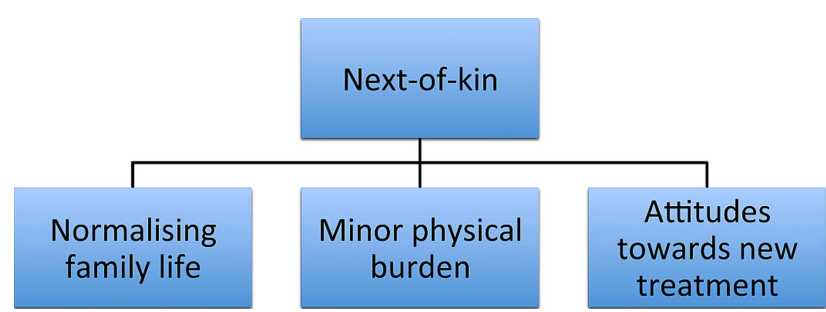

Figure 2 Experiences of next-of-kin. Main categories emerging from the interviews. 
being discharged: "I started driving again much earlier this time, you are not supposed to do that when you have had an open-chest operation. Nor can you can lift heavy things for quite some time, as an example I was not able to lift up my own children when I wanted".

Five of the boys (7), median age 18 years (7-28), in the study referred mainly to physical endurance when asked about improvements after the percutaneous intervention. This was unlike girls (3), median age 17 years (10-30), who emphasised the possibility of taking part socially as the main issue. Adults (2) commented on how fewer symptoms gave psychosocial benefits shortly after treatment. There was a gender difference on how patients described improvements after treatment and how these improvements influenced their daily lives.

\section{Prospects of future treatment}

Surgery was often referred to as a major trauma involving tissue matters. The experiences and future prospects of repeated major surgeries were associated with anxiety and insecurity. Renewed hope towards treatment options was stated "I think technology evolves in many areas and I don't think I have to be afraid." Another statement was: "It doesn't matter if they have to intervene once more, as long as they fix it I am happy." One of the adult patients said: "Not any special expectations, usually things work out. Things often take time-I have been in the system for some time and that is how it is in a way."

\section{Experiences of close relatives}

The main finding was the significance of normalisation. The normalisation of the psychological performance of their child led to a normalisation of their family life. Second, the minor physical burden with little pain was highlighted. Third, the positive attitude towards this new treatment and renewed hope towards treatment options in the future, were the main themes evolving throughout the interviews.

\section{Normalising family life}

All next-of-kin strongly expressed the importance of normalising everyday life. All parents expressed that they laid down a lot of resources both economically and timewise in order to normalise their childrens' lives and thereby trying to create a normal family situation. This seemed to be a part of a preventative health strategy concerning both their family and society: "It is obvious that if you miss out from school 3-4 weeks after treatment, you loose a lot of opportunities, both in school, among friends and in different ways. After surgery in 2006 our daughter was sort of switched out of her social life." Another statement was: "For the family's sake, the avoidance of spending a lot of time in hospital was of great importance. The organizing at home with siblings was easier after the percutaneous implantation." Nine $(50 \%)$ of the parents stated in different ways that they would recommend the percutaneous option as it simplifies everyday life for the parents as well as the patient.
One father expressed it like this: "Being a parent and having a job waiting for you, it is not uncomplicated to be away 2 till 4 weeks. We have extended days of incapacity as parents, still we do not want to use them if we don't have to. To get away with an intervention is "worth gold'."

\section{Minor physical burden}

Minimal pain and an easy rehabilitation decreased the physical burden. Five parents stated that increased mobility, flexibility and almost non-existence of pain during the rehabilitation period, made the percutaneous implantation technique attractive. One parent stated "The rehabilitation phase is different. She went to see a friend the same day she was discharged from hospital. She had a bruise in her groin for a few days, that was all. She told herself that she would rather have 10-20 new bruises than one new open-chest operation." One father explained his experience after percutaneous pulmonary valve implantation in his daughter: "The relief of not having to see your daughter in pain and avoiding a stay in the intensive care unit, was a big relief. To see your child in such a situation is quite stressful for parents. I think this is the most important issue from my point of view. Another statement was: "After the percutaneous pulmonary valve implantation, she told it hurt a bit when walking the first day after the intervention, that was all."

\section{Attitudes towards the new treatment}

Despite a positive attitude, the next-of-kin visualised vulnerability and insecurity being a parent or close relative to a patient with a chronic disease requiring repeated surgeries and hospital stays. Conflicting thoughts of life and death when leaving their child in the operating theatre were described. Being among the first patients treated with this technique, parents and other next-of-kin were left in a situation of insecurity, hoping for a gentler pathway for their child. Three of the parents did not seem to be able to differ, or to know what to expect differently of these two treatment methods before the admission. The differences were first appreciated after the percutaneous pulmonary valve implantation was completed successfully. One couple of parents described their thoughts about the device equipment as follows: "When we saw the new device equipment, we thought the introduction cable looked massive and far to big to use. But then the doctor explained and showed us how it was done. Our daughter seemed calm and confident with the information he gave her, and we decided to put our trust in the medical team." Another couple explained how they felt when they first heard of the percutaneous pulmonary valve: "As long as it is a minor intervention, it is worth a try. If this had been more complicated, it would probably not have been wise to be among the first ones treated with this new intervention. Anything that makes things easier, is good." The value and need of trust to healthcare providers are 
shown in the citing above with the parent's main focus on the wellbeing of their child.

\section{DISCUSSION}

This study demonstrates the impact of a chronic disabling disease requiring repeated surgeries on the patient's and next-of-kin's daily life and the priorities they have to make. Patients with congenital heart disease today have a longer life expectancy than before. ${ }^{3}$ Along with the longer life expectancy comes frequent hospitalisations and repeated surgical interventions. ${ }^{6}$

Regular check-ups and unexpected complications can lengthen the hospitalisation duration. ${ }^{12}$ Medical complications, ventricular failure and arrhythmias are common. ${ }^{13}$ Many of these events may cause a temporary set-back in the patient's physical function, and thereby causing an interruption in the patient's and the next-of-kin's social life. With this background it is not surprising that the experience of regaining a functional role and returning to normal life 3 days after treatment was embraced as the most important asset of the percutaneous valve technique by the patients and the next-of-kin. The importance of regaining physical control as fast as possible after treatment, has previously been documented in other patients with congenital heart disease. ${ }^{10}$

Previous studies show that the patients with congenital heart disease try to compensate for the lack of physical performance by adapting to alternative roles during physical activity and pursuing academic interests in order to obtain social recognition. ${ }^{8}{ }^{9}$ In this context it is interesting that in the present study we found a difference between genders in their evaluation of the benefit of the minimal invasive technique. While the males emphasised the physical improvements as a major benefit, the females claimed the possibility of taking part in their social arenas as the most important consequence of the minimal invasive treatment.

Several studies indicate that patients with chronic cardiac disease are at risk of having poorer educational and vocational outcomes as compared with healthy young adults. ${ }^{13-15}$ There may be many causes for this phenomenon. The interruption of the school year by repeated controls and treatments is obviously a factor, but some authors have also emphasised the effect on the cognitive function of having repeated open heart surgeries. ${ }^{69}$

An important consequence of the percutaneous technique as experienced by the patients was their ability to follow the school year. Another possible advantage of this technique is that the valve implantation is performed by venous insertion at the right side of the heart, thus not affecting the arterial side. ${ }^{16}$ One would thus expect a lesser challenge of the cognitive function after treatment compared to open surgery including the use of extracorporeal circulation.

The transition from adolescence to adulthood is a major challenge. Peer support and social activities with close friends appear to be important for keeping up a normal maturation progress and handling challenges associated with adolescence. ${ }^{689}$ In accordance with this several of the patients mentioned the importance of being able to visit their friends immediately after the treatment. Overgaard et al referring experiences of young adults with single ventricle physiology, state that respondents underscored the need for friends and resource persons to lift them out of their role as disabled cardiac patients and provide them with 'normal' life experiences. ${ }^{9}$

For the adult patients, the main benefit of the treatment was their ability to continue with and mastering their daily chores such as tending to their children, driving their car or maintaining their social life. They emphasised the psychological impact of not being able to do that after open heart surgery. Previous studies also demonstrate that family, education, career, friends and healthcare are rated among the most important domains to have an impact on quality of life for adult patients. ${ }^{17} 18$ Social adjustment, academic progress, future employment as well as health insurance and life insurance are also major challenges for this group. ${ }^{6} 101920$

For the parents and next-of-kin living in close relationship with a patient with congenital heart disease this is a challenge, thus the next-of-kin also emphasised the minimal disruption of the family life as a main benefit of the minimal invasive method. The family members were able to maintain an almost normal everyday life following the hospitalisation. The quick recovery with no stay in the intensive care unit after treatment was appreciated. The parents referred to these benefits as "worth gold' for the family, but also for their own career and their relation with their employer, as they were able to go to work with little interruption. The striving for life normality is essential for this patient population. Normalisation seemed to be a management strategy of the patients and their family. Because of a minor interference on daily life, the minimal invasive technique was experienced as important for their strive for normality.

Acknowledgements The authors are grateful to the participations in this study that generously shared their experience. Also we are grateful to Jacob Bergsland for proofreading the manuscript. Finally we thank Marianne Berg for transcription of the interviews.

Collaborators BA; MHA; HL; GD; EF.

Contributors $\mathrm{BA}, \mathrm{MHA}, \mathrm{HL}$ and $\mathrm{EF}$ made substantial contributions to the conception of the study. All authors contributed in the study design process. $\mathrm{BA}, \mathrm{MHA}, \mathrm{GD}$ and $\mathrm{EF}$ were responsible for data acquisition. BA and MHA made substantial contributions in the analysis data process, but all authors participated to strengthen accurate reflection, highlight differences, provided critical revisions for the content and approved the final version.

Funding South-Eastern Norway Regional Health Authority.

Competing interests None.

Patient consent Obtained.

Ethics approval The study was approved by the Regional Committee for Medical Research Ethics in South-East Norway.

Provenance and peer review Not commissioned; externally peer reviewed.

Data sharing statement No additional data are available. 
Open Access This is an Open Access article distributed in accordance with the Creative Commons Attribution Non Commercial (CC BY-NC 3.0) license, which permits others to distribute, remix, adapt, build upon this work noncommercially, and license their derivative works on different terms, provided the original work is properly cited and the use is non-commercial. See: http:// creativecommons.org/licenses/by-nc/3.0/

\section{REFERENCES}

1. Moons $\mathrm{P}$, Bovijn L, Budts $\mathrm{W}$, et al. Temporal trends in survival to adulthood among patients born with congenital heart disease from 1970 to 1992 in Belgium. Circulation 2010;122:2264-72.

2. Brickner ME, Hillis LD, Lange RA. Congenital heart disease in adults. First of two parts. N Engl J Med 2000;342:256-63.

3. Moons P, Sluysmans T, De WD, et al. Congenital heart disease in 111225 births in Belgium: birth prevalence, treatment and survival in the 21st century. Acta Paediatr 2009:98:472-7.

4. Lurz $\mathrm{P}$, Bonhoeffer $\mathrm{P}$, Taylor AM. Percutaneous pulmonary valve implantation: an update. Expert Rev Cardiovasc Ther 2009;7:823-33.

5. Moola F, McCrindle BW, Longmuir PE. Physical activity participation in youth with surgically corrected congenital heart disease: devising guidelines so Johnny can participate. Paediatr Child Health 2009;14:167-70.

6. Callus E, Quadri E, Chessa M. Elements of psychocardiology in the psychosocial handling of adults with congenital heart disease. Front Psychol 2010;1:34.

7. Vergales JE, Wanchek T, Novicoff W, et al. Cost-analysis of percutaneous pulmonary valve implantation compared to surgical pulmonary valve replacement. Catheter Cardiovasc Interv 2013;82:1147-53.

8. Bjørkmo W, Engelsrud G. I am almost like a fish: an investigation of how children with congenital heart disease experience and perform movement in daily life. Child Care Health Dev 2008;34:781-8.
9. Overgaard D, King C, Christensen RF, et al. Living with half a heart-experiences of young adults with single ventricle physiology: a qualitative study. J Cardiovasc Nurs 2013;28:187-96.

10. Shearer K, Rempel GR, Norris CM, et al. "It's No Big Deal": adolescents with congenital heart disease. J Pediatr Nurs 2013;28:28-36.

11. Kvale S, Brinkmann S. Interviews: learning the craft of qualitative research interviewing. Los Angeles: Sage Publications, 2009.

12. Callus E, Quadri E, Chessa M. [Psychosocial difficulties and hospitalisation experiences in adults with congenital heart disease. The utility of psychological interventions]. Pediatr Med Chir 2010;32:305-8.

13. Human DG. Living with complex congenital heart disease. Paediatr Child Health 2009:14:161-82.

14. Forrest CB, Bevans KB, Riley AW, et al. Health and school outcomes during children's transition into adolescence. J Adolesc Health 2013;52:186-94.

15. Claessens $\mathrm{P}$, Moons $\mathrm{P}$, de Casterle BD, et al. What does it mean to live with a congenital heart disease? A qualitative study on the lived experiences of adult patients. Eur J Cardiovasc Nurs 2005;4:3-10.

16. Bonhoeffer $\mathrm{P}$, Boudjemline $\mathrm{Y}$, Saliba Z, et al. Percutaneous replacement of pulmonary valve in a right-ventricle to pulmonary-artery prosthetic conduit with valve dysfunction. Lancet 2000;356:1403-5

17. Moons $\mathrm{P}$, Van DK, Marquet $\mathrm{K}$, et al. Individual quality of life in adults with congenital heart disease: a paradigm shift. Eur Heart $J$ 2005;26:298-307.

18. Loup O, von WC, Gahl B, et al. Quality of life of grown-up congenital heart disease patients after congenital cardiac surgery. Eur $J$ Cardiothorac Surg 2009;36:105-11.

19. Immer FF, Althaus SM, Berdat PA, et al. Quality of life and specific problems after cardiac surgery in adolescents and adults with congenital heart diseases. Eur J Cardiovasc Prev Rehabil 2005;12:138-43.

20. Crossland DS, Jackson SP, Lyall R, et al. Life insurance and mortgage application in adults with congenital heart disease. Eur $J$ Cardiothorac Surg 2004;25:931-4. 